\title{
Acute kidney failure and acute pancreatitis was caused after neoadjuvant therapy for a patient with Breast Cancer】a case report
}

\section{Shuo Liang ( $\sim$ liangshuo96@qq.com )}

Nanjing University of Chinese Medicine https://orcid.org/0000-0001-5650-5145

Ting Ni

Affiliated Hospital of Nanjing University of Chinese Medicine: Jiangsu Province Academy of Traditional Chinese Medicine

Chang Yao

Affiliated Hospital of Nanjing University of Chinese Medicine: Jiangsu Province Academy of Traditional Chinese Medicine

\section{Research Article}

Keywords: Breast cancer, Neoadjuvant therapy, Carboplatin, Acute kidney failure, acute pancreatitis

Posted Date: February 8th, 2022

DOI: https://doi.org/10.21203/rs.3.rs-1117144/v1

License: (c) (1) This work is licensed under a Creative Commons Attribution 4.0 International License. Read Full License 


\section{Abstract}

Background: Acute kidney injury (AKI) is a common adverse reaction of platinum drugs in neoadjuvant chemotherapy for breast cancer patients. Approximately $30 \%$ of patients receiving cisplatin have acute kidney injury. Carboplatin have less nephrotoxic than cisplatin as the second generation platinum compound. There were AKI, nausea and vomiting, acute pancreatitis and oral ulcers occurred in a women who had intravenous carboplatin in our department.

Case presentation: A 63 year-old Chinese female had neoadjuvant chemotherapy of TCbHP because of diagnosed with stage III breast invasive ductal carcinoma with axillary lymph node metastasis. Fourth day after chemotherapy, she had fatigue and nausea and then suffered from AKI, acute pancreatitis and mouth ulcers. After active treatment in the ICU and breast disease department, the patient's condition improved and was discharged.

Conclusion: Although carboplatin, as a second-generation platinum drug, has less nephrotoxicity than cisplatin, it still needs special attention to avoid damage to the kidneys in clinical citation. At the same time, due to the killing effect of chemotherapeutics on the body's normal immune cells, other abnormal conditions in the body should be paid special attention to avoid more serious consequences.

\section{Introduction}

In neoadjuvant chemotherapy for breast cancer patients, acute kidney injury is a common adverse reaction of platinum drugs. Approximately $30 \%$ of patients receiving cisplatin have acute kidney injury. Carboplatin is the second generation platinum compound, which has been certificated to have less nephrotoxic than cisplatin. One of the mechanism of cisplatin nephropathy is that cisplatin is taken into the proximal renal tubule epithelial cells via organic cation transporter 2 (OCT 2) on the tubular basolateral membrane, and mitochondrial DNA damage and apoptosis are induced. This article reports a case of acute renal failure caused by carboplatin, followed by acute pancreatitis and oral ulcers and other adverse complications. The reasons for the situation and the prevention and treatment of Chinese and Western medicine are discussed.

At the same time, after cisplatin is deposited in cells, it can cause acute tubular necrosis through inflammation and oxidative stress. In contrast, carbo-platin is not transported by OCT 2 and has been suggested to reduce nephrotoxicity due to low tubular accumulation[1, 2]. Till this moment, articles about carboplatin-induced kidney injury are not common. This article reports a case of acute renal failure caused by carboplatin, nausea and vomiting and later adverse complications such as acute pancreatitis and oral ulcers, and discuss the reasons for such situations and how to prevent and treat them with Chinese and Western medicine.

\section{Case Presentation}

A 63 year-old female presented to Department of Breast Diseases, Jiangsu Province Hospital of Chinese Medicine, with complaints of discovery of Breast lumps of 6 months duration(Figure 1). The patient denied any special past medical history but the glycosylated hemoglobin is higher than normal after admission $\square$ Table 1区.In order to clarify the pathological nature of the mass, the patient was performed core needle

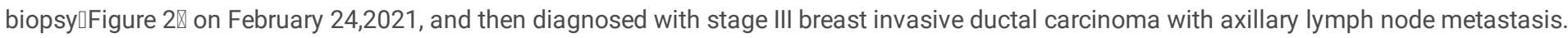

Decision of multidisciplinary meeting was to start with neoadjuvant chemotherapy of TCbHP. She received her first cycle of double targets therapy with 440mg Herceptin and 840mg Pertuzumabon on March 05, 2021 and first cycle of chemotherapy with 110mg Docetaxel and 500mg Carboplatin on March 06,2021. Then he left the hospital on March 08.

On the second day after leaving the hospital, she felt fatigued, nausea and vomiting 3-5 times a day after eating. The vomit was stomach contents, and diarrhea 4-6 times a day, the excrement initially look yellow and soft, and then turned to yellow watery stool. This condition lasted for 7 days and she did not ask for any system therapy during this period.

The patient went to local hospital and got blood routine examination and blood biochemistry on March,15,2021(Table 1).Because of the

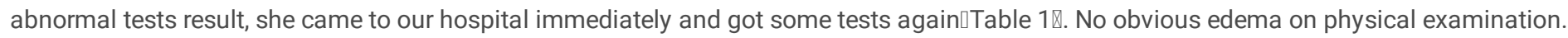
According to her symptoms, physical signs and auxiliary examination, she was diagnosed as $₫$ Breast malignancy $\llbracket$ Metabolic acidosis $₫$ Hyponatremia囚Hypokalemia And then she was treated with rehydration therapy, antacids, hepatoprotective treatment, ECG monitoring, oxygen inhalation, blood glucose monitoring and so on. Then we transferred her to Intensive Care Unit after consulting with ICU and communicatng with her family members so that she can get more professional and timely treatment and we can prevent her condition getting worse.

In ICU, she was diagnosed as $₫$ Breast malignancy $₫$ Acute renal failure $₫$ Electrolyte disturbance $₫$ Metabolic acidosis $\varangle$ Hyponatremia $\nabla$ Hypokalemia $\varangle$ Stress hyperglycemia and she was treated with anti-infective, blood sugar regulation, rehydration therapy, anticoagulant, electrolyte balance adjustment, nutritional support. After about 4 days of treatment, the patient recovered gradually(Table 1), and then she was transferred back to Department of Breast Diseases after system evaluation on March,18,2021. 
For the purpose of evaluating the risk of venous thrombosis due to long-term bedridden, necessary imaging studies were performed which revealed abnormal pancreas and peripancreatic adipose space(Figure 3).Investigations revealed increased amylase levels and lipase levels $\square$ Table $2 \bigotimes$.She told us she had suffered from gallbladder stones for about 20 years and eat too much greasy meat recently after we make a detailed inquiry about her medical history. After consulting with department of gastroenterology, we considered that there was a sudden onset of acute pancreatitis in this patient and we treated her with fasting, pancreatic juice secretion inhibition, electrolyte disorders correction, electrolyte balance adjustment. She recovered soon. 


\begin{tabular}{|c|c|c|c|c|c|c|c|}
\hline & $2021-02-24$ & $2021-03-08$ & 2021-03-15 & 2021-03-15 & $\begin{array}{l}2021- \\
03-15\end{array}$ & $\begin{array}{l}2021- \\
03-16\end{array}$ & $\begin{array}{l}2021- \\
03-17\end{array}$ \\
\hline & $\begin{array}{l}\text { After the first } \\
\text { hospital admission }\end{array}$ & $\begin{array}{l}\text { After the first } \\
\text { Neoadjuvant Therapy }\end{array}$ & $\begin{array}{l}\text { Before the second } \\
\text { hospital admission }\end{array}$ & $\begin{array}{l}\text { After the second } \\
\text { hospital admission }\end{array}$ & \multicolumn{3}{|c|}{ After transfer to ICU } \\
\hline $\begin{array}{l}\mathrm{CRP} \\
\mathrm{mg} / \mathrm{l}\end{array}$ & & 1.10 & & 0.89 & & 164.97 & 90.34 \\
\hline $\begin{array}{l}\text { WBC } \\
* 10^{9} / \mathrm{L}\end{array}$ & 7.63 & 6.41 & 17.83 & 16.26 & & 12.67 & 11.66 \\
\hline $\begin{array}{l}\text { RBC } \\
\star 10^{12} / \mathrm{L}\end{array}$ & 4.49 & 4.43 & 5.12 & 5.18 & & 4.15 & 3.89 \\
\hline $\mathrm{HGB} g / \mathrm{L}$ & 130 & 127 & 141 & 144 & & 116 & 105 \\
\hline $\begin{array}{l}\text { NEUT } \\
\star 10^{12} / \mathrm{L}\end{array}$ & 6.16 & 6.02 & 15.84 & 14.03 & & 11.93 & 10.50 \\
\hline $\begin{array}{l}\text { MONO } \\
\star 10^{9} / \mathrm{L}\end{array}$ & 0.16 & 0.12 & 0.76 & 1.77 & & 0.57 & 0.75 \\
\hline $\begin{array}{l}\text { LY } \\
* 10^{9} / \mathrm{L}\end{array}$ & 1.26 & 0.27 & & 0.45 & & 0.16 & 0.30 \\
\hline NEUT \% & 80.7 & 93.9 & & 86.2 & & 94.1 & 90.1 \\
\hline $\begin{array}{l}\text { MONO } \\
\%\end{array}$ & 2.1 & 1.9 & & 2.8 & & 1.3 & 6.4 \\
\hline LY \% & 16.5 & 4.2 & & 10.9 & & 4.5 & 2.6 \\
\hline AST U/L & 26 & 29 & & 31 & & 19 & 38 \\
\hline ALT U/L & 53 & 69 & & - & & 27 & 34 \\
\hline $\begin{array}{l}\text { CR } \\
\text { umol/L }\end{array}$ & 71.9 & 61.9 & 331 & 204.2 & & 228.5 & 156.0 \\
\hline $\begin{array}{l}\text { BUN } \\
\text { mmol/L }\end{array}$ & 5.04 & 8.2 & 55.2 & 59.6 & & 46.45 & 30.66 \\
\hline $\begin{array}{l}\mathrm{UA} \\
\mathrm{mmol} / \mathrm{L}\end{array}$ & 304 & 276 & 983 & 974 & & 860 & 478 \\
\hline CK U/L & 124 & & 812 & 780 & & 613 & 613 \\
\hline CK-MB & 178 & & & 23 & & 22 & \\
\hline LDH U/L & 178 & & 339 & 1111 & & 312 & \\
\hline $\begin{array}{l}\mathrm{GLU} \\
\mathrm{mmol} / \mathrm{L}\end{array}$ & 6.15 & 8.63 & 20.88 & 23.2 & & 4.22 & 12.50 \\
\hline GLB g/L & 21.6 & 29.0 & & & & 16.0 & 19.7 \\
\hline ALB g/L & 46.50 & 43.0 & 36 & 37.0 & & 37.5 & 35.60 \\
\hline TP & 46.50 & 72.0 & - & 68.0 & & 55.51 & 55.27 \\
\hline $\begin{array}{l}\mathrm{Na}^{+} \\
\mathrm{mmol}\end{array}$ & 140.5 & 137.8 & 120 & 118 & 126.7 & 136.0 & 157.7 \\
\hline $\begin{array}{l}\mathrm{Cl}^{-} \\
\mathrm{mmol} / \mathrm{L}\end{array}$ & 104.7 & 103.8 & 84 & 89 & 99 & 107.4 & 120.9 \\
\hline $\begin{array}{l}\mathrm{P} \\
\mathrm{mmol} / \mathrm{L}\end{array}$ & 0.93 & 1.15 & 3.04 & 3.75 & & 0.97 & 0.55 \\
\hline $\begin{array}{l}\mathrm{Mg}^{2+} \\
\mathrm{mmol} / \mathrm{L}\end{array}$ & 1.01 & 0.88 & 1.60 & 1.56 & & 0.80 & 1.36 \\
\hline $\mathrm{K}^{+}$ & 3.89 & 4.52 & - & 3.45 & 2.98 & 3.40 & 3.70 \\
\hline
\end{tabular}




\begin{tabular}{|c|c|c|c|c|c|c|c|}
\hline & $2021-02-24$ & 2021-03-08 & 2021-03-15 & 2021-03-15 & $\begin{array}{l}2021- \\
03-15\end{array}$ & $\begin{array}{l}2021- \\
03-16\end{array}$ & $\begin{array}{l}2021- \\
03-17\end{array}$ \\
\hline $\mathrm{Ca}^{2+}$ & 2.39 & 2.23 & - & 1.05 & 0.98 & 2.27 & 1.98 \\
\hline $\mathrm{pH}$ & & & - & 7.246 & 7.368 & 7.329 & \\
\hline $\begin{array}{l}\mathrm{pCO}_{2} \\
\mathrm{mmHg}\end{array}$ & & & - & 17.3 & 19.7 & 18.3 & \\
\hline $\begin{array}{l}\mathrm{pO}_{2} \\
\mathrm{mmHg}\end{array}$ & & & - & 119.7 & 245.9 & 184.4 & \\
\hline $\begin{array}{l}\mathrm{HCO}_{3}^{-} \\
\mathrm{mmol} / \mathrm{L}\end{array}$ & & & - & 7.3 & 11.1 & 21.0 & \\
\hline SO2 & & & - & 98.2 & 99.4 & & \\
\hline $\begin{array}{l}\mathrm{tHb} \\
\mathrm{g} / \mathrm{dL}\end{array}$ & & & & & 12.2 & 12.1 & \\
\hline $\begin{array}{l}\mathrm{Lac} \\
\mathrm{mmol} / \mathrm{L}\end{array}$ & & & & 2.22 & 2.04 & 1.72 & \\
\hline $\begin{array}{l}\mathrm{SBE}^{-} \\
\mathrm{mmol} / \mathrm{L}\end{array}$ & & & & & -14.2 & -16.5 & \\
\hline $\begin{array}{l}\mathrm{ABE}^{-} \\
\mathrm{mmol} / \mathrm{L}\end{array}$ & & & & & -12.0 & & \\
\hline РCT & & & & & & 6.86 & 5.04 \\
\hline$\underset{\%}{\mathrm{HbA} A \mathrm{C}}$ & 6.5 & & 8 & & & & \\
\hline
\end{tabular}

Table 2

\begin{tabular}{|c|c|c|c|c|c|c|c|c|c|c|c|c|c|c|c|}
\hline & $\begin{array}{l}2021- \\
03-15\end{array}$ & $\begin{array}{l}2021- \\
03-16\end{array}$ & $\begin{array}{l}2021- \\
03-17\end{array}$ & $\begin{array}{l}2021- \\
03-19\end{array}$ & $\begin{array}{l}2021- \\
03-20\end{array}$ & $\begin{array}{l}2021- \\
03-22\end{array}$ & $\begin{array}{l}2021- \\
03-23\end{array}$ & $\begin{array}{l}2021- \\
03-24\end{array}$ & $\begin{array}{l}2021- \\
03-26\end{array}$ & $\begin{array}{l}2021- \\
03-29\end{array}$ & $\begin{array}{l}2021- \\
03-31\end{array}$ & $\begin{array}{l}2021- \\
04-02\end{array}$ & $\begin{array}{l}2021- \\
04-05\end{array}$ & $\begin{array}{l}2021- \\
04-07\end{array}$ & $\begin{array}{l}2021- \\
04-08\end{array}$ \\
\hline $\begin{array}{l}\text { AMS } \\
\text { U/L }\end{array}$ & 209 & 171 & 444 & 771 & 317 & 117 & 79 & 53 & 89 & 54 & 47 & 41 & 38 & 68 & 67 \\
\hline $\begin{array}{l}\text { LPS. } \\
\text { U/L }\end{array}$ & 2012 & 598 & 1904 & 1454 & 580 & 59 & 71 & 54 & 53 & 104 & 78 & 82 & 59 & 474 & 419 \\
\hline
\end{tabular}

There was another trouble happened to her that the patient started to suffer from dental ulcer with a mass of purulent secretion on March,20,2021. We tested the germ of the purulent secretion and did drug sensitive test which showed Candida albicans infection,then gave her suitable anti-infective treatment.

Take this adverse reaction into consideration, multidisciplinary meeting decided to change the chemotherapy regimen, to use PHP instead of TCbHP. The patient has received 4 cycles of double targets therapy and 4 cycles of chemotherapy without any other adverse reaction until now.

\section{Discussion}

TCbHP consists of Docetaxel, Carboplatin, Pertuzumab and Trastuzumab. Carboplatin, a new AnAlogue of cisplatin used in the treatment of breast carcinoma, is the second generation platinum compound, which has been certificated to have less nephrotoxic than cisplatin. The major side effects of Carboplatin are myelosupression and gastrointestinal effects. Nephrotoxicity, neurotoxicity, hematotoxicity, anaphylactic reaction can also be seen[3].

Firstly, no matter in clinical research or in the researches carried out in the laboratory, there are many reports about the impairment of kidney function even acute renal failure caused by carboplatin[[4-8], which is rare in adverse reactions of the remaining three drugs. Secondly, in the process of recording the medical history, the patient denied the history of diabete, but blood glucose monitoring shows the patient may have diabete(Table 1), which may blow up the drug damage to the kidney at a reasonable dose[9].So we consider that there is the acute kidney injury happened to this patient owing to Carboplatin. 
Many experiments show that the metabolism of Carboplatin mainly depends on the kidney, but how Carboplatin causes nephrotoxicity is not fully revealed, which is believed to be owing to both direct and indirect damage to the kidneys including drug absorption and transport, oxidative stress of renal proximal tubule epithelial cells, apoptosis and inflammatory response[10-12]. However, because of the lower nephrotoxicity than Cisplatin, acute kidney injury(AKI) caused by Carboplatin, including acute tubular necrosis can not be seen often[5].

Normally, according to the location and cause of the disease, AKI can be divided into three categories: Prerenal AKI, Renal AKI, Postrenal AKI. Acute kidney injury caused by drug factors may be the main reason of this case. There are three cases reported to be proved acute interstitial nephritis (AIN) by performing a percutaneous renal biopsy[5, 13]. In this case, we focused on the treatment of the condition instead of judgment of the lesion, so we did not perform analogous biopsy to establish an accurate diagnosis.

In order to prevent and handle this emergency situations, we can choose both conventional medication or treatment and traditional chinese medicine treatment and nursing. On one hand, we can use pentoxifylline-non-specific phosphodiesterase inhibitor or pravastatin as adjuvant drugs[13-15]or giving plenty of water $\square$ adding magnesium to reduce kidney damage[16, 17], and if AKI has happened, we should remove the cause $\llbracket$ correct electrolyte imbalance or choose symptomatic drugs even alternative therapy. On the other hand, traditional chinese medicine treatment and nursing can also be useful. For example, according to the traditional Chinese medicine"look, smell, ask and cut"on physique screening and judgment, individual guidance for life and health can be carried on to protect kidney. Medicina diet is also suitable for patients to regulate the physique[18]. For example, astragalus carp soup can invigorate the spleen, nourish qi and yin, dispel dampness, promote diuresis, and increase the growth of qi and blood. Carp, adzuki bean, lotus seeds, ginger and other medicines and foods are homologous, so it is safe and effective with long-term consumptio[19]. At the same time, acupuncture point massage at Neiguan point $[$ Laogong point $\square$ Guanyuan point $\square$ Shenshu point can be good choice for patients, we can choose Shuifen point \Yanglingquan point $\square$ Jianli point as an assistant in edema period[20]. For the low creatinine clearance, retention enema with Serissa foetida Comn\Rheum officinale[Coptic and Scutellaria baicalensis will be beneficial[21].

Chemotherapy-related nausea and vomiting(CINV)is the most common adverse reactions of Carboplatin, which is one of the middle-to-high grade emetic chemotherapeutic drugs. When the area under the curve is less than 4, the incidence of CINV is 65\%[22].Diarrhea is also one of the common adverse reactions of Carboplatin-Docetaxel combination[23]. At the same time, AKI can also been seen nausea, vomiting and diarrhea as its first symptoms[24]. Currently, serotonin receptor antagonists like Tropisetron,Ondansetron,and Granisetron is common and the symptomatic treatment of Traditional Chinese medicine treatment is superior to western medicine in some occasions when it comes to treatment,such as Shenque acupoint can be selected in acupoint sticking therapy with a mixture of cornus officinails, cumin and ginger juice once a day, the yang deficiency patients can be treated with moxibustion three strong every time[25, 26].

Taking the side effects of these drugs the patient used into consideration[27-31], the symptoms of acute pancreatitis the patient had is more relevant to irregular diet and history of gallbladder stones.

The key reason why chemotherapeutics can treat tumor diseases is that they can inhibit the proliferation of cancer cells and use drugs to inhibit the division of cancer cells. Because chemotherapy drugs are often used systemically, the oral mucosa with similar proliferation characteristics of tumor cells is the first to be attacked[32].The reduced immunity the chemotherapeutics caused, and the reduced barrier function on account of the damage of Oral mucosa cells, which are both in favor of the bacteria or fungi infection[33].

When we discuss the cause of these symptoms, we should take the drugs the patient used and the histories into consideration.

\section{Conclusions}

This article reports on a case of breast cancer patient with nausea, vomiting, acute renal failure, acute pancreatitis and oral ulcers and other adverse reactions after neoadjuvant chemotherapy of TCbHp regimen. Through analysis of symptoms, signs, auxiliary examinations and clinical medications, it is believed that the most likely cause of acute renal failure in patients is carboplatin, and how to judge the injury site and how to prevent and treat it clinically is discussed. At the same time, the causes of adverse complications such as nausea, vomiting and oral ulcers caused by chemotherapy and the prevention and treatment of traditional Chinese and Western medicine have been discussed. In this article, the patient's acute pancreatitis is more likely to have a history of improper diet before admission and a history of gallbladder stones than the side effects of chemotherapy drugs. Through reporting and discussion, clinical treatment can be guided in future treatments.

\section{Abbreviations}

AKI

Acute kidney injury

TCbHp

A chemotherapy regimen, Docetaxel combined with carboplatin, combined with trastuzumab and pertuzumab ECG

Page 6/10 
electrocardiogram

ICU

Intensive Care Unit

CINV

Chemotherapy-related nausea and vomiting

\section{Declarations}

\section{Ethics approval and consent to participate}

Not applicable

\section{Consent for publication}

Not applicable

\section{Availability of data and material}

All data generated or analysed during this study are included in this published article.

\section{Competing interests}

The authors declare that they have no competing interest.

\section{Funding}

This study is supported by National Natural Science Foundation of China(k2018GR11).

\section{Authors' contributions}

TN contributed to conception of the manuscript and writing of TCM characteristic therapy. SL contributed to analysis and drafting of the manuscript. SL made the figure and table.CY revised the manuscript. All authors read and approved the final manuscript.

\section{Acknowledgements}

Written consent was obtained from the patient for publication of study.

\section{References}

1. Fujishiro $\mathrm{H}$, et al. Comparisons of segment-specific toxicity of platinum-based agents and cadmium using $\mathrm{S} 1, \mathrm{~S} 2$, and $\mathrm{S} 3$ cells derived from mouse kidney proximal tubules. Toxicol In Vitro. 2021;75:105179.

2. López Quiñones AJ, Wagner DJ, Wang J. Characterization of Meta-lodobenzylguanidine (mIBG) Transport by Polyspecific Organic Cation Transporters: Implication for mIBG Therapy. Mol Pharmacol. 2020;98(2):109-19.

3. Kooijmans EC, et al., Early and late adverse renal effects after potentially nephrotoxic treatment for childhood cancer. Cochrane database of systematic reviews (Online), 2019. 3(7).

4. Fu Y, et al. Chronic effects of repeated low-dose cisplatin treatment in mouse kidneys and renal tubular cells. Am J Physiol Renal Physiol. 2019;317(6):F1582-f1592.

5. Asai A, et al., Carboplatin-related acute interstitial nephritis in a patient with pancreatic neuroendocrine tumor. CEN Case Reports, 2020. 9(2).

6. D'Amelio CM, et al. Utility of delayed reading of intradermal test in carboplatin-induced drug hypersensitivity. Ann Allergy Asthma Immunol. 2015;114(6):534-5.

7. Page EE, et al. Quinine-Induced Thrombotic Microangiopathy: A Report of 19 Patients. Am J Kidney Dis. 2017;70(5):686-95.

8. Abid H, Kumar A, Patel A. Metastatic Rectal Small Cell Carcinoma: A Case Report. Cureus, 2020. 12(7).

9. in LiverTox: Clinical and Research Information on Drug-Induced Liver Injury. 2012, National Institute of Diabetes and Digestive and Kidney Diseases: Bethesda (MD).

10. Oun, et al., The side effects of platinum-based chemotherapy drugs: a review for chemists. Dalton Transactions An International Journal of Inorganic Chemistry, 2018.

11. Ehrmann S, et al. Nephrotoxic drug burden among 1001 critically ill patients: impact on acute kidney injury. Annals of Intensive Care. 2019;9(1):106. 
12. Vaz NF, et al. Evolution of diagnostic criteria for acute kidney injury in patients with decompensated cirrhosis: A prospective study in a tertiary university hospital. Clin Res Hepatol Gastroenterol. 2020;44(4):551-63.

13. Sasaki T, et al. Two cases of cisplatin-induced permanent renal failure following neoadjuvant chemotherapy for esophageal cancer. Int $J$ Surg Case Rep. 2016;20:63-7.

14. Khakhariya R, et al. Carboplatin-induced Fanconi-like syndrome in rats: Amelioration by pentoxifylline. Environmental Toxicology Pharmacology. 2014;37(1):185-94.

15. Chen $\mathrm{HH}$, Chen TW, Lin H. Pravastatin attenuates carboplatin-induced nephrotoxicity in rodents via peroxisome proliferator-activated receptor alpha-regulated heme oxygenase-1. Mol Pharmacol. 2010;78(1):36-45.

16. AlMahruqi, et al. Renoprotective Effects of Gamma-Aminobutyric Acid on Cisplatin-induced Acute Renal Injury in Rats. Basic \& clinical pharmacology \& toxicology; 2015.

17. Tatsuya Y, et al., Protective effect of magnesium preloading on cisplatin-induced nephrotoxicity: a retrospective study. Japanese Journal of Clinical Oncology, 2014(4): p. 346-54.

18. Huang P. Protective effect of traditional Chinese medicine Huangqi and Danggui mixture on renal injury in nephrotic syndrome. Oriental Medicated Diet. 2020;11:55.

19. Chen XY, Qiu Y, Wang Y. Clinical observation on astragalus carp soup diet prescription auxiliary treatment for edema in nephrotic syndrome patients. CHINESE NURSING RESEARCH, 2012. 26(3): pp. 249-50.

20. Shen YL, Du WW. Clinical Study on the Effect of Acupoint Application and Massage Combined with Intensified Health Education to Intervene Chronic Renal Failure. Self Care. 2021;8:57.

21. Chu C, W and Cui AG. Clinical Observation on the Treatment of Chronic Renal Failure with Ziwuliu Injection and Colon Retention Enema. Guangming Journal of Chinese Medicine. 2019;34(16):2445-7.

22. Breast Cancer Group. O.B.o.C.M.D.A., Expert consensus on the clinical application of platinums in advanced breast cancer (2020 version). Clinical Medicine of China. 2021;37(2):97-105.

23. Giannakakis T, et al. Docetaxel in combination with carboplatin for the treatment of advanced non-small cell lung carcinoma: a multicentre phase I study. Eur J Cancer. 2000;36(6):742-7.

24. Ashley, Farrar. Acute Kidney Injury. The Nursing clinics of North America; 2018.

25. Zhang L. Research Progress of Acupoint Application of Chinese Herbal Medicine in Treatment of Chronic Kidney Disease and Its Complications. Hunan Journal of Traditional Chinese Medicine. 2016;32(6):190-3.

26. Jianfang XU, Yanhong QB,NI. Clinical Study on Point Application with Chinese Herbal Medicine Combined with Bushen Huazhuo Tang for Chronic Renal Failure. Journal of New Chinese Medicine. 2021;53(6):121-4.

27. Baker J, et al. Docetaxel-related side effects and their management. European Journal of Oncology Nursing. 2009;13(1):49-59.

28. Popat S, Smith IE. Therapy Insight: anthracyclines and trastuzumab--the optimal management of cardiotoxic side effects. Nat Clin Pract Oncol. 2008;5(6):324-35.

29. Moilanen, et al. Trastuzumab-induced cardiotoxicity and its risk factors in real-world setting of breast cancer patients. Journal of Cancer Research \& Clinical Oncology; 2018.

30. Gao J, Swain SM. Pertuzumab for the treatment of breast cancer: a safety review. Exp Opin Drug Saf. 2016;15(6):853-63.

31. Woodward N, et al. Management of patients treated with pertuzumab in the Australian clinical practice setting. Asia-Pacific Journal of Clinical Oncology. 2016;12:5-15.

32. Rímulo A. and M.C. Ferreira... Chemotherapy-induced oral mucositis in a patient with acute lymphoblastic leukaemia. European Archives of Paediatric Dentistry. 2011;12(2):124-7.

33. Yan L, Hsu K, Beckman RA. Antibody-based therapy for solid tumors. Cancer J. 2008;14(3):178-83.

\section{Figures}



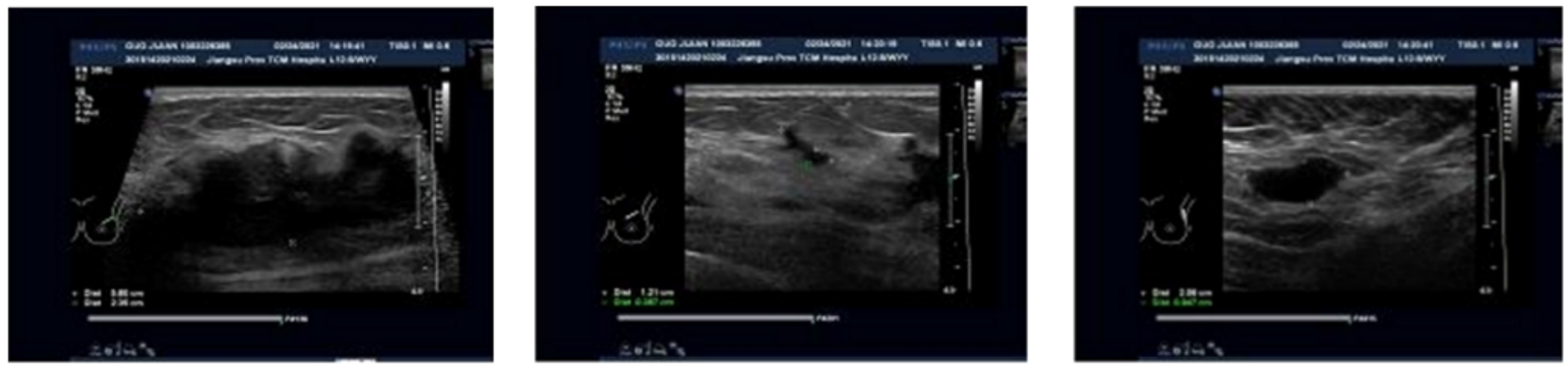

\section{Figure 1}

Color Doppler ultrasound of breast on February,24,2021

$1 \mathrm{a} \otimes \mathrm{A}$ hypoechoic zone about $5.1 \mathrm{~cm} \star 3.8 \mathrm{~cm} \star 2.4 \mathrm{~cm}$ in the upper left breast

Blurred edges, Uneven internal echo and scattered dotted strong echo in the hypoechoic zone and echo attenuation behind the zone.

CDFI: The lesion is of abundant blood flow signals, which show a high impedance.

$1 \mathrm{~b} \llbracket \mathrm{A}$ hypoechoic zone about $1.2 \mathrm{~cm} * 0.4 \mathrm{~cm}$ in the upper left breast

$1 \mathrm{c} \bowtie$ Several Oval hypoechoic areas in the left breast axilla $\$ one of them is about $2.1 \mathrm{~cm} * 0.9 \mathrm{~cm}$

Smooth edges, evenly thickened cortex and disappearance of lymphatic hilum structure

CDFI: The lesion is of none flow signals.
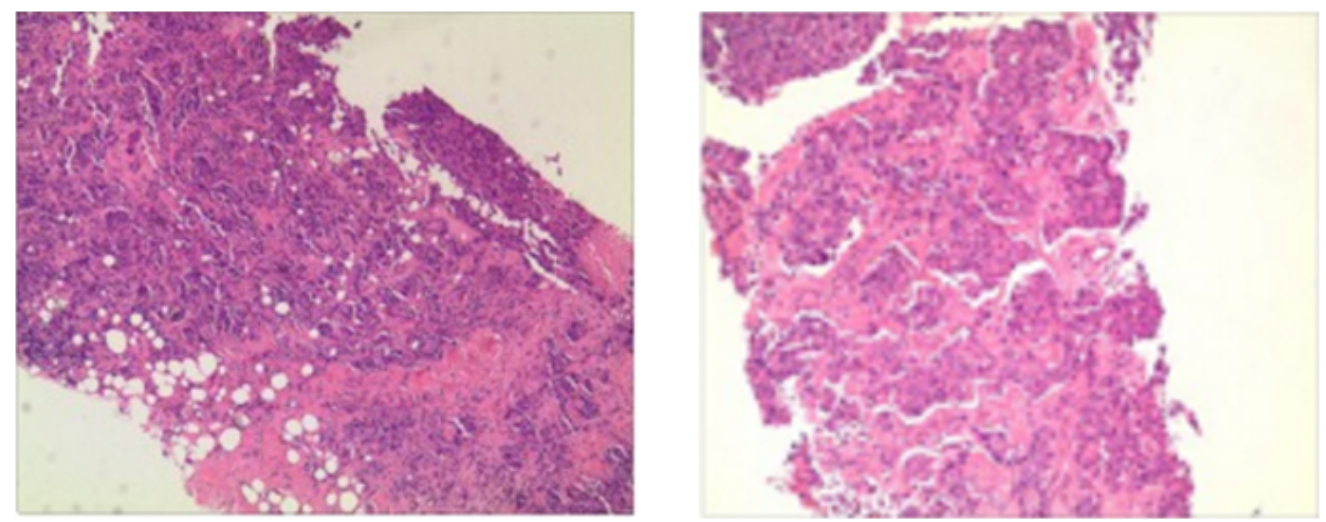

Figure 2

Pathological report of hollow needle puncture on the upper left breast mass and left axillary lymph node

2a囚Left breast puncture specimen

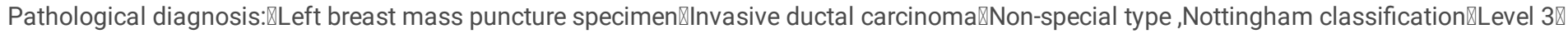

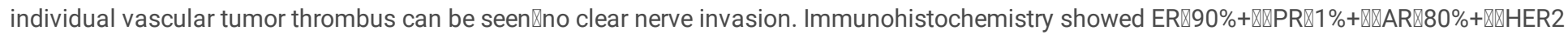

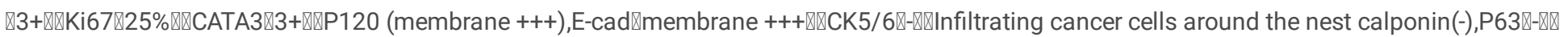
CD310D2-40 Mark the vessel.

2b囚Left axillary lymph node puncture specimen

Pathological diagnosis: (Puncture tissue of left axillary lymph node)Invasive ductal carcinoma邓Non-special type ,Nottingham classification $₫$ Level

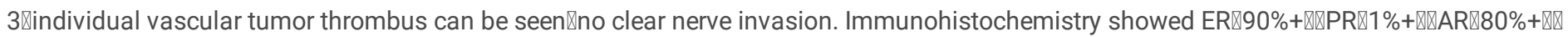

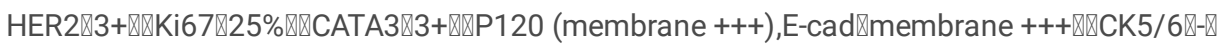



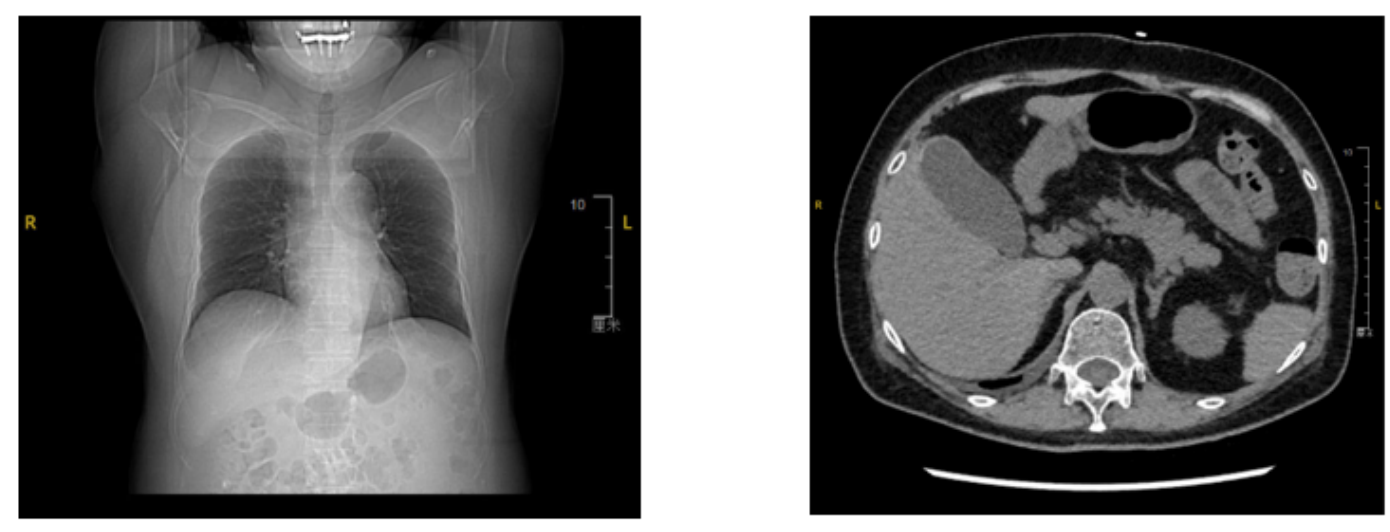

Figure 3

Large pancreatic head, fuzzy peripancreatic fat space, and thickened bilateral prerenal fascia 